\title{
Qualitative and Quantitative Study of Quercetin and Glycyrrhizin in In Vitro Culture of Liquorice (Glycyrrhiza glabra L.) and Elicitation with $\mathrm{AgNO}_{3}$
}

\author{
Farnaz TAHOORI ${ }^{1}$, Ahmad MAJD ${ }^{2 *}$, Taher NEJADSATTARI ${ }^{1}$, \\ Hamideh OFOGHI $^{3}$, Alireza IRANBAKHSH ${ }^{1}$ \\ ${ }^{I}$ Islamic Azad University, Science and Research Branch, Department of Biology, Tehran, Iran; f.farnaztahoori@gmail.com; \\ nejadsattari_t@yahoo.com;iranbakhshar@yahoo.com \\ ${ }^{2}$ Islamic Azad University, North Tehran Branch, Department of Biology, Tehran, Iran; abmadmajd537@gmail.com (“correspondingauthor) \\ ${ }^{3}$ Iranian Research Organization for Science and Technology (IROST), Department of Biotechnology, Tehran, Iran; ofoghi@irost.ir
}

\begin{abstract}
Liquorice (Glycyrrhiza glabra L.) is a plant that has been considered for a long time due to its valuable secondary metabolites. This study was conducted to obtain quercetin and glycyrrhizin under controlled conditions and the use of silver nitrate $\left(\mathrm{AgNO}_{3}\right)$ as an elicitor to increase their production. For this purpose, the seeds were cultured in MS media containing various concentrations of $\mathrm{AgNO}_{3}\left(0,2,4,8\right.$ and $\left.10 \mathrm{mg} \mathrm{L} \mathrm{L}^{-1}\right)$. Quercetin in the aerial parts extract of three-month seedlings prepared with methanol solvent $95 \%$ and acetic acid (9:1), and glycyrrhizin in the root extract of four-month seedlings prepared with ethanolic extract (30\%) were evaluated qualitatively and quantitatively using HPLC. The results obtained from three replications showed the presence of quercetin and glycyrrhizin in all samples. The amount of quercetin in all samples treated with $\mathrm{AgNO}_{3}$ was significantly higher than control $(\mathrm{P} \leq 0.05)$ and this increase was higher at concentrations of 8 and 10 $\mathrm{mg} \mathrm{L}^{-1}$ in comparison with other concentrations. Glycyrrhizin content increased under the influence of different concentrations of $\mathrm{AgNO}_{3}$ as compared to the control; however, this increase was not significant. Our results clearly showed that this method is a practical method to produce and elicit more these compounds with medicinal value.
\end{abstract}

Keywords: anti-ethylene; biotechnology; elicitor; flavonoids; high performance liquid chromatography; non-biological stresses; terpenoids

Abbreviations: $\mathrm{AgNO}_{3}$ : Silver nitrate; ANOVA: Analysis of variance; HPLC: High performance liquid chromatography; L: Liter; $\mu$ : micro; m: milli 10 $0^{-3}$; mol: mole; MS: Murashige and Skoog nutrient medium; nm: nanometer; ROS: Reactive oxygen species; SE: Standard error; SOD: Superoxide dismutase; UV: Ultraviolet; v: volume; w: weight

\section{Introduction}

Plants are the source of a large group of organic compounds called secondary metabolites. The studies have shown that the market value of herbal medicines is always on the rise worldwide with substantial growth, and much of it is related to the production and supply of secondary metabolites derived from plants (Schäfer and Wink, 2009; Seca and Pinto, 2018; Yang et al., 2018). The complexity and costly chemical synthesis of the compounds (Smetanska, 2008; Kanwal and Sherazi, 2017) as well as their slow formation has led to an interest in using various methods of biotechnology including seeds, organs, tissues and cells culture for mass and fast production of these compounds under in vitro conditions (Naik and Al-Khayri, 2016). In this regard, manipulation of the medium and the use of elicitors (Tiwari and Rana, 2015) such as $\mathrm{AgNO}_{3}$ with features including ease of access, solubility in water, and stability (Kumar et al., 2009) could be helpful for mass production of these metabolites (Bota and Deliu, 2011; Naik and Al-Khayri, 2016). There are several reports on increased production of secondary metabolites in plants by using $\mathrm{AgNO}_{3}$ elicitor (Ramirez-Estrada et al., 2016; Shakeran et al., 2015; Patel and Krishnamurthy, 2013).

Liquorice (Glycyrrbiza glabra L.) is a perennial species belonging to the Fabaceae family. As an industrial plant, it is 
144

of interest to pharmaceutical and food industries. The plant height is up to $200 \mathrm{~cm}$. Leaves are compound, flowers are purple and fruits are $2 \mathrm{~cm}$ long. It is a Mediterranean plant, growing in South Asia and from southern Europe to central Asia (Karaogul et al., 2016; Dastgir and Rizvi, 2016). So far, more than 300 types of flavonoids have been reported from different species of the genus Glycyrrhiza, of which 70 have been extracted from Glycyrrbiza glabra (Fukai et al., 1998; Ranganathan and Punniamurthy, 2013). Flavonoids are secondary metabolites that are physiologically important for plants. They increase plant resistance to stress (Treutter, 2006; Mierziak et al., 2014) and are involved in pollination, seed dispersal and thus in plant reproduction (Raja and Sreenivasulu, 2015). These compounds are also important in flower color determination (Panche et al., 2016), protect the plant cells against oxidative damage, and increase the efficiency of nutrient absorption at the time of aging (Feild et al., 2001). Protection of plants against pathogens and herbivores and involvement in plant competition and symbiosis of plants and microbes are other features of flavonoids (Wink, 2010; Mierziak et al., 2014). These compounds are also used in the treatment of many human diseases (Kumar and Pandey, 2013; Zeka et al., 2017).

Quercetin is a flavonoid. This compound is a strong dietary supplement and antioxidant, cleaning up the body from free radicals that cause cancer and diseases such as atherosclerosis. Furthermore, it is helpful to deal with viruses and lower the blood pressure (Edwards et al., 2007; Larson et al., 2010). In addition, this drug compound prevents the release of histamine, an inflammatory substance involved in allergic symptoms such as itching and sneezing (Maalik et al., 2014; Mlcek et al., 2016). Anti-aging property of quercetin is also reported by some researchers (Chondrogianni et al., 2010; Nagaich et al., 2016). In some studies, the presence of quercetin in liquorice has been reported (Singh et al., 2009; Khalaf et al., 2010).

Terpenoids are the largest class of natural compounds that are made of mevalonic acid pathway and plants use these compounds in growth, but their main role is to preserve the plant against a variety of biological and nonbiological stresses (Tholl, 2015). Glycyrrhizin or glycyrrhizic acid is a terpenoid compound with the molecular formula of $\mathrm{C}_{42} \mathrm{H}_{62} \mathrm{O}_{16}$ and the most important ingredient in the root of Glycyrrhiza glabra, making it sweet. Glycyrrhizin has medicinal properties in humans including antioxidant and anti-cancer, anti-viral, anti-hepatitis, anti-skin allergies, antiinflammatory, anti-wound, and anti-peptic ulcers. Glycyrrhizin is also used as a food sweetener (Tian et al., 2008; Shabani et al., 2009; Liao et al., 2016).

Regarding the importance of liquorice as a medicinal plant, this research was aimed to investigate the quercetin and glycyrrhizin quantitatively and qualitatively under in vitro condition and also study the effects of $\mathrm{AgNO}_{3}$ elicitor at different concentrations $\left(0,2,4,8,10 \mathrm{mg} \mathrm{L}^{-1}\right)$ on increased production of these secondary metabolites in this species.

\section{Materials and Methods}

Preparation of seeds and cultivation conditions

The seeds of Glycyrrbiza glabra were procured from Isfahan
PakanBazr Company (Isfahan, Iran) and surface-sterilized with sodium hypochlorite (3\%) for three minutes. Then, the seeds were rinsed with distilled water several times and cultured in plates with a diameter of $8 \mathrm{~cm}$, containing MS medium (Murashige and Skoog, 1962) and various concentrations of $\mathrm{AgNO}_{3}\left(0,2,4,8,10 \mathrm{mg} \mathrm{L}^{-1}\right)$. All culture media contained $3 \%$ sucrose and $0.8 \%$ agar $(\mathrm{w} / \mathrm{v})$. The $\mathrm{pH}$ was adjusted to 5.8. The media were autoclaved at 1 atmosphere and $121{ }^{\circ} \mathrm{C}$ for 20 minutes. The plates containing culture media and seeds were placed under a photoperiod of 16 hours light (using 36-watt fluorescent lamps at a distance of $30 \mathrm{~cm}$ from the samples) and 8 hours darkness at $28 \pm 2{ }^{\circ} \mathrm{C}$.

\section{Extractspreparation}

To evaluate the quercetin qualitatively and quantitatively, after 3 months of seed culture, $0.1 \mathrm{~g}$ of dried powder of aerial parts (leaves and stems) were poured into lidded test tubes and $1.5 \mathrm{~mL}$ of methanol-acetic acid at a ratio of 9:1 ( $\mathrm{v} / \mathrm{v})$ was added to each sample. The test tubes containing dried powder of aerial parts and solvent were placed in water bath at $50^{\circ} \mathrm{C}$ for 20 minutes (Dmitriensko et al., 2012; Jaimand et al., 2013).

In order to qualitative and quantitative studies on glycyrrhizin, dried and powdered roots of four-month seedlings were used. For this purpose, $0.04 \mathrm{~g}$ dry powder of roots and $2 \mathrm{ml}$ of ethanol solution (30\%) were poured into the test tubes and mixed with a shaker several times and placed at $50{ }^{\circ} \mathrm{C}$ for one hour (Tian et al., 2008). The extracts, obtained by BioFIL filters with a diameter of 0.45 $\mathrm{m} \mu$, were kept in the refrigerator until injection into the HPLC.

\section{HPLC conditions}

Isolation of quercetin and glycyrrhizin was performed by high-performance liquid chromatography (HPLC) from Knauer Company (Berlin, Germany). Detection was made by a UV / V is detector set to $290 \mathrm{~nm}$ for quercetin and 254 $\mathrm{nm}$ for glycyrrhizin. The column was C18 $(250 \times 4.6 \mathrm{~mm}$, $30{ }^{\circ} \mathrm{C}$ ) with a pump (model K-1001). Methanol-wateracetic acid at a ratio of 50:45:5 (v/v / v) was used as the mobile phase for quercetin and $20 \mu \mathrm{l}$ was injected. For glycyrrhizin, the mobile phase included methanol-water $(30: 70, \mathrm{v} / \mathrm{v})$ and $1 \%$ acetic acid that $50 \mu \mathrm{l}$ was injected. For both compounds, the flow rate was $1 \mathrm{~mL} / \mathrm{sec}$ and the experiments lasted 30 minutes.

\section{Preparation of standards and calibration curves}

Quercetin with molecular formula $\mathrm{C}_{15} \mathrm{H}_{10} \mathrm{O}_{7}$ and molecular weight of $302.24 \mathrm{~g} / \mathrm{mol}$ was used as quercetin standard. It was purchased at 10 grams from Sigma-Aldrich. Concentrations of 5, 10,20,40,80 mg of standard sample were prepared in one liter of methanol-acetic acid (9:1, v / v) and injected to the HPLC. The quercetin content was calculated based on the equation of the standard curve and the area under spectrums.

Ammonium salt of glycyrrhizic acid $\left(\mathrm{C}_{42} \mathrm{H}_{65} \mathrm{NO}_{16}\right)$ with molecular weight of $839.96 \mathrm{~g} / \mathrm{mol}$ at $25 \mathrm{~g}$ with brand Sigma-Aldrich was used as glycyrrhizin standard. This compound was used at concentrations of 10, 20, 30, 40 , and $50 \mathrm{mg}$, solved in one liter of ethanol solvent (30\%) and injected to the device to draw the calibration line curve 
of glycyrrhizin. Then, the glycyrrhizin content in samples was calculated based on the equation of the standard curve and the area under spectrum.

\section{Experimental design and statistical analysis}

Preparation of culture media containing various concentrations of $\mathrm{AgNO}_{3}\left(0,2,4,8,10 \mathrm{mg} \mathrm{L}{ }^{-1}\right)$ with 6 seeds in each plate were performed three times with three replications for each group and each time, a culture medium containing different concentrations of $\mathrm{AgNO}_{3}$ and seeds was considered as a replicate. The data were analyzed by analysis of variance (ANOVA) and the means were compared with Duncan's Multiple Range Test $(\mathrm{P} \leq 0.05)$ using SPSS software V.16. Charts were drawn in the EXCEL 2007 software.

\section{Results}

HPLC chromatograms for quercetin and glycyrrbizin standards

According to the HPLC chromatograms for quercetin standard solutions with different concentrations, maximum absorption was detected approximately 13 minutes after injection (Fig. 1A). The calibration curve, curve line equation $(Y=7811.5 x+4970.9)$, and regression coefficient $\left(R^{2}=96.34\right)$ for quercetin standard solutions are shown in Fig. 2A.

According to the HPLC chromatograms for glycyrrhizin standard solutions at different concentrations, maximum absorption was detected approximately 24 minutes after injection (Fig. 1B). The calibration curve, curve line equation $(\mathrm{Y}=18401 \mathrm{x}-21698)$, and regression coefficient $\left(\mathrm{R}^{2}=0.97\right)$ for glycyrrhizin standard solutions are shown in Fig. 2B. These curves of two compounds show good linearity and regression coefficients.

\section{HPLC chromatograms for quercetin and glycyrrbizin}

Figs. 3 and 4 show the three-month and four-month seedlings derived from the growth of seeds at different concentrations of $\mathrm{AgNO}_{3}$ in which quercetin and glycyrrhizin were investigated qualitatively and quantitatively in the aerial parts (leaves and stems) and root extracts, respectively. Chromatograms of quercetin spectra, at various concentrations of $\mathrm{AgNO}_{3}\left(0,2,4,8,10 \mathrm{mg} \mathrm{L}^{-1}\right)$, indicated the presence of this compound in the extracts of aerial parts of seedlings with an absorption peak in approximately the thirteenth minute (Fig. 5A-E).

A

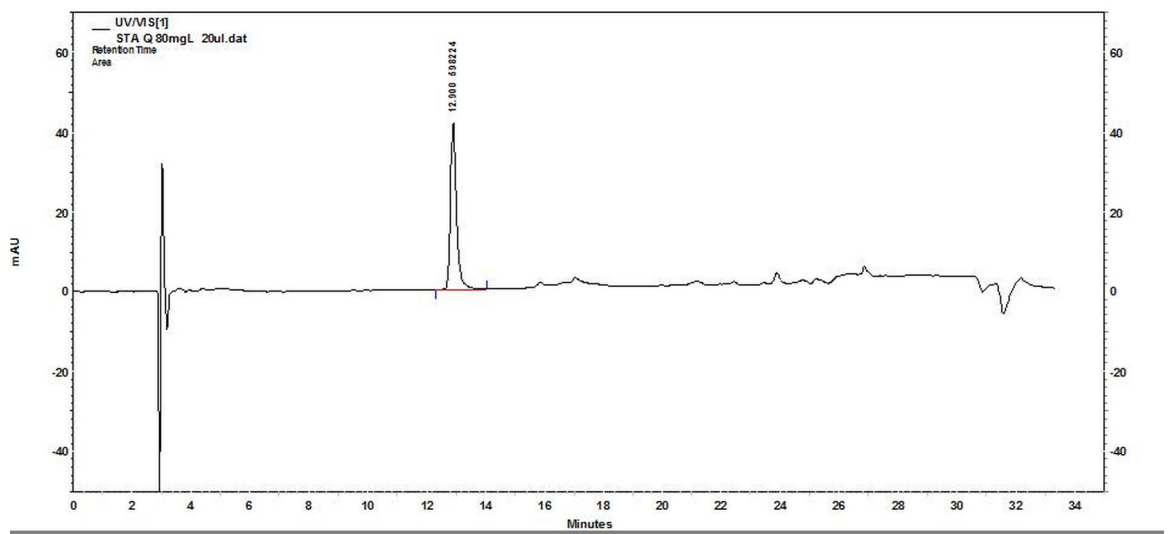

B

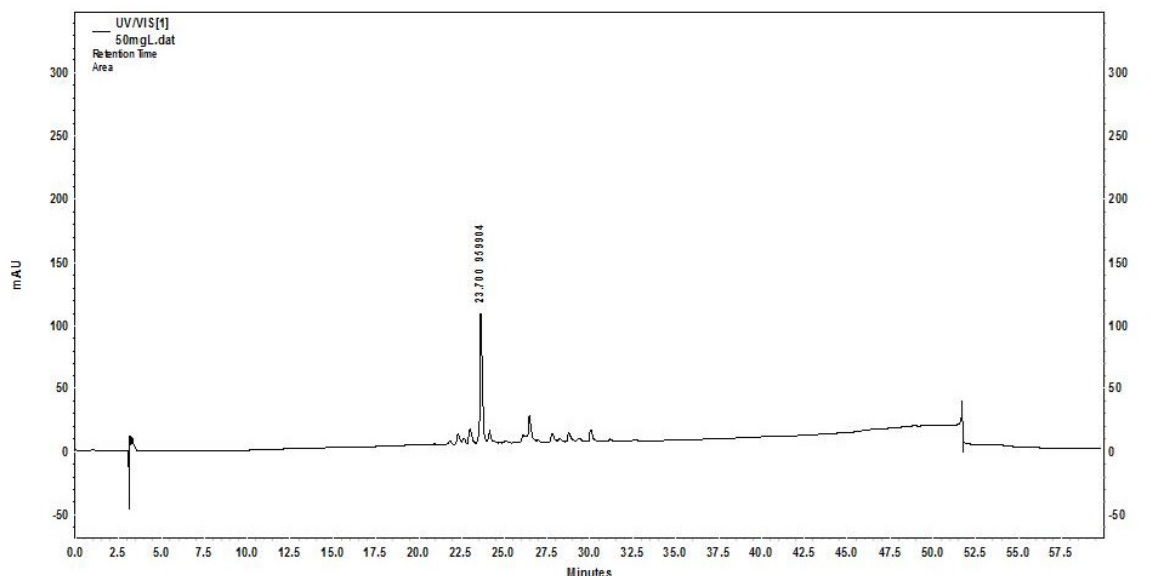

Fig. 1. Spectrum chromatograms of quercetin (A) and glycyrrhizin (B) standards. The y-axis of the chromatogram is the intensity of quercetin and glycyrrhizin absorptions (Area) in unit of milli-Absorbance Unit (mAU). The $\mathrm{x}$-axis determines the Retention Time (RT) in unit of minute. The amount of injected sample for quercetin is $20 \mu \mathrm{L}$ and for glycyrrhizin is $50 \mu \mathrm{L}$. For quercetin standard, maximum absorption is approximately 13 minutes after injection and for glycyrrhizin standard, it is approximately 24 minutes after injection 
B

A

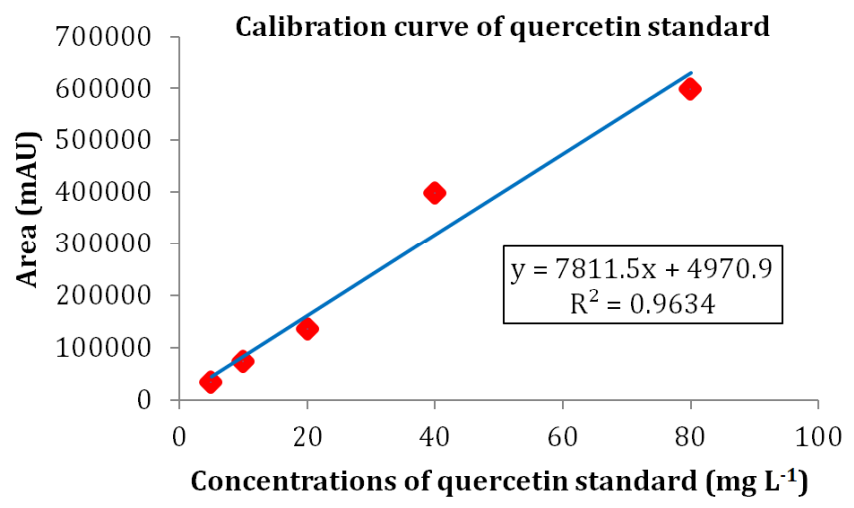

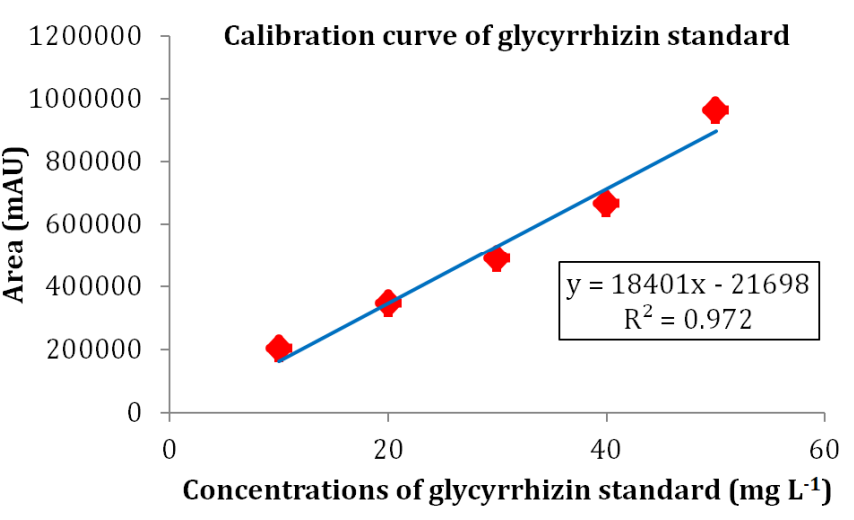

Fig. 2. A: Calibration curve of quercetin standard in different concentrations $\left(5,10,20,40\right.$ and $\left.80 \mathrm{mg} \mathrm{L}^{-1}\right)$ and the regression equation $(y=7811.5 x+4970.9)$ with regression coefficient $\left(\mathrm{R}^{2}=0.9634\right)$. B: Calibration curve of glycyrrhizin standard in different concentrations $\left(10,20,30,40\right.$ and $\left.50 \mathrm{mg} \mathrm{L}^{-1}\right)$ and the regression equation $(y=18401-21698)$ with regression coefficient $\left(\mathrm{R}^{2}=0.972\right)$. These curves of two compounds show good linearity and regression coefficients

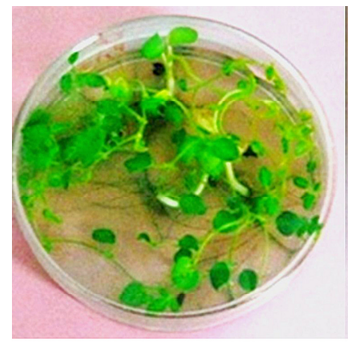

A

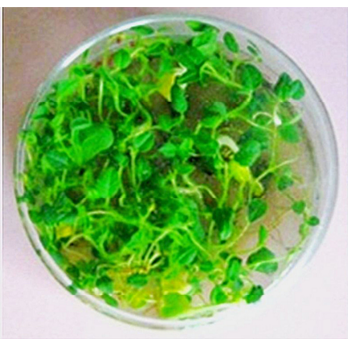

B

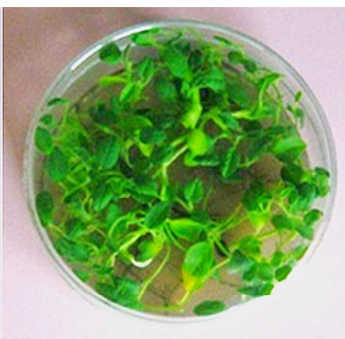

C

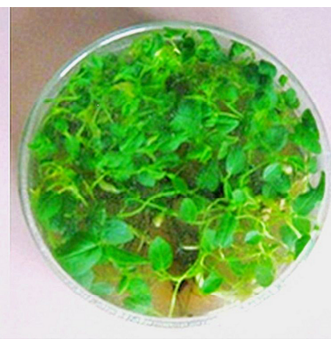

D

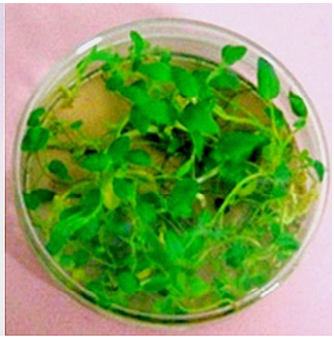

E

Fig. 3. Three-month-old seedlings of Glycyrrhiza glabra in MS medium containing different concentrations of $\mathrm{AgNO}_{3}$ for qualitative and quantitative studies on quercetin. $0 \mathrm{mg} \mathrm{L}^{-1}(\mathrm{~A}), 2 \mathrm{mg} \mathrm{L}^{-1}(\mathrm{~B}), 4 \mathrm{mg} \mathrm{L}^{-1}(\mathrm{C}), 8 \mathrm{mg} \mathrm{L}^{-1}(\mathrm{D}), 10 \mathrm{mg} \mathrm{L}^{-1}(\mathrm{E})$

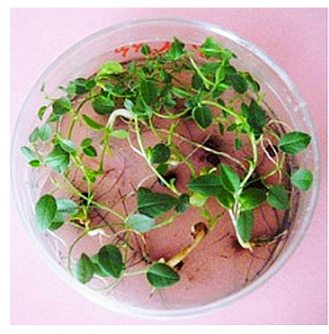

A

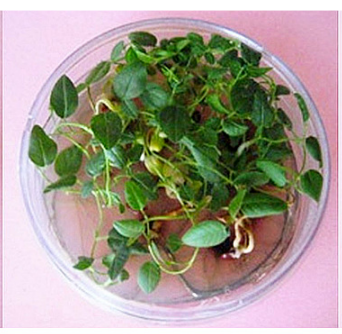

B

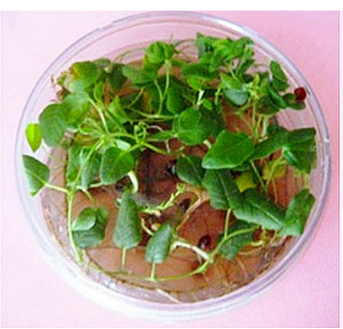

C

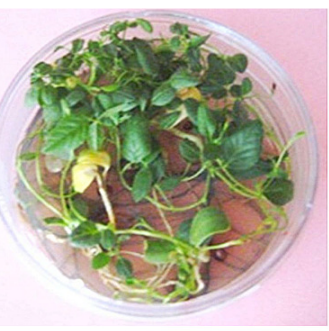

D

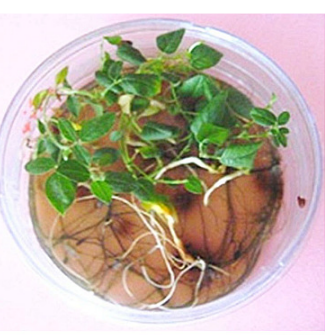

E

Fig. 4. Four-month-old seedlings of Glycyrrhiza glabra in MS medium containing different concentrations of $\mathrm{AgNO}_{3}$ for qualitative and quantitative studies on glycyrrhizin. $0 \mathrm{mg} \mathrm{L}^{-1}(\mathrm{~A}), 2 \mathrm{mg} \mathrm{L}^{-1}(\mathrm{~B}), 4 \mathrm{mg} \mathrm{L}^{-1}(\mathrm{C}), 8 \mathrm{mg} \mathrm{L}^{-1}(\mathrm{D}), 10 \mathrm{mg} \mathrm{L}^{-1}(\mathrm{E})$

According to the results, the mean maximum absorption at different concentrations of $\mathrm{AgNO}_{3}$ was higher as compared with control samples. In addition, the content of quercetin significantly increased at concentrations of 2 (5.94 \pm 0.8$), 4$ (5.20 \pm 0.3$), 8$ (10.74 \pm 0.8$)$, and 10 (10.95 $\pm 1.1) \mathrm{mg} \mathrm{L}^{-1}$ to compared with control group $(2.45 \pm 0.5)$ $(\mathrm{P} \leq 0.05)$. Furthermore, the difference between concentrations of 2 and $4 \mathrm{mg} \mathrm{L}^{-1}$ with 8 and $10 \mathrm{mg} \mathrm{L}^{-1}$ was significant. No significant difference was found between concentrations of 2 and $4 \mathrm{mg} \mathrm{L}^{-1}$ as well as between concentrations of 8 and $10 \mathrm{mg} \mathrm{L}^{-1}$ (Fig. 7A).
Chromatograms of the glycyrrhizin spectrum at various concentrations of $\mathrm{AgNO}_{3}\left(0,2,4,8,10 \mathrm{mg} \mathrm{L}^{-1}\right)$, showed the presence of this compound in the root extract of seedlings with the appearance of absorption peaks in approximately the twenty-fourth minute (Fig. 6A-E). According to the results, the content of glycyrrhizin insignificantly increased at concentrations of $2(8.31 \pm 1.1)$, $4(9.59 \pm 1.5), 8(9.08 \pm 1.2)$, and $10(8.13 \pm 0.3) \mathrm{mg} \mathrm{L}^{-1}$ to compared with control group $(8.05 \pm 1.3)$ (Fig. $7 \mathrm{~B})$. 


\section{Discussion}

The results of this study clearly showed the presence of quercetin and glycyrrhizin in control samples and those treated with $\mathrm{AgNO}_{3}$. In addition, increased content of these secondary metabolites in the treated samples was observed compared to controls. In some reports it has been shown that the production of secondary metabolites in plants is a sign of cell differentiation (Bourgaud et al., 2001). Due to the slow formation of these compounds in nature, the use of biotechnology including seed, tissue, and cell culture under in vitro conditions could result in faster production of these compounds and increase the possibility of access to natural medicines with no side effects (Rates, 2001; Zhao et al., 2005).Thus, the presence of quercetin and glycyrrhizin in all samples could be attributed to the in vitro culture and accelerated growth of plants. Furthermore, it is proven that

A

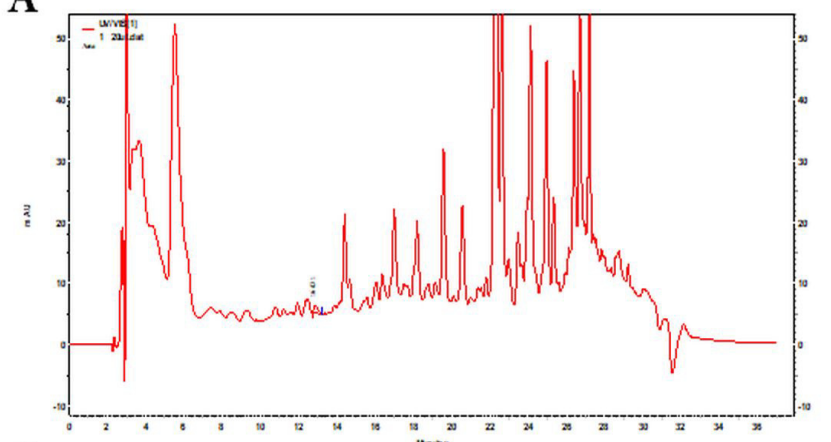

C

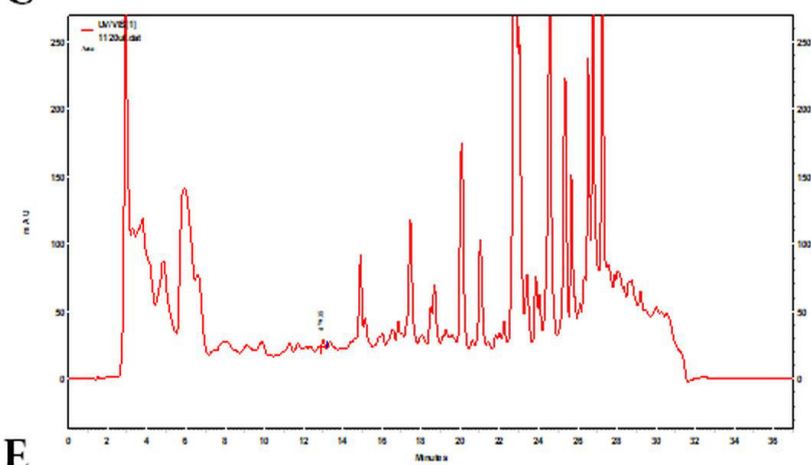

$\mathbf{E}$

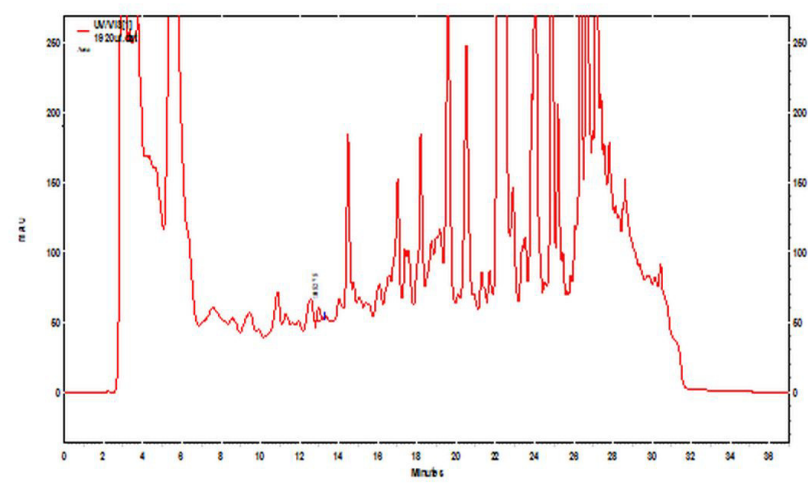

the use of elicitors such as salts of heavy metals including $\mathrm{AgNO}_{3}$ can cause messages to induce the production of secondary metabolites (Bota and Deliu 2011; Vildova et al., 2016).

Silver is a heavy metal with a molecular weight of $107.868 \mathrm{gmol}^{-1}$ and a density of $10.5 \mathrm{gcm}^{-3}$ and the most important form in nature is nitrate (Bais et al., 2000). Studies have shown that the ions of heavy metals such as silver can cause oxidative stress induction (Fuente et al., 2014). Under oxidative stress conditions, the production of reactive oxygen species (ROS) is the first process occurring within cells based on stress intensity and physicochemical conditions (Zhao et al., 2005; Tripathy and Oelmüller, 2012; Sewelam et al., 2016), causing damage to DNA, structural proteins and lipids and induction of out-ofcontrol chain reactions such as oxidation and peroxidation (Sharma et al., 2012; Tripathy and Oelmüller, 2012;

B

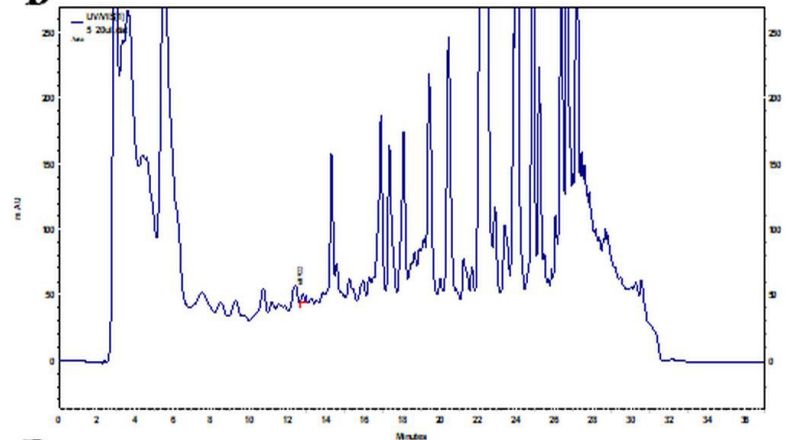

D

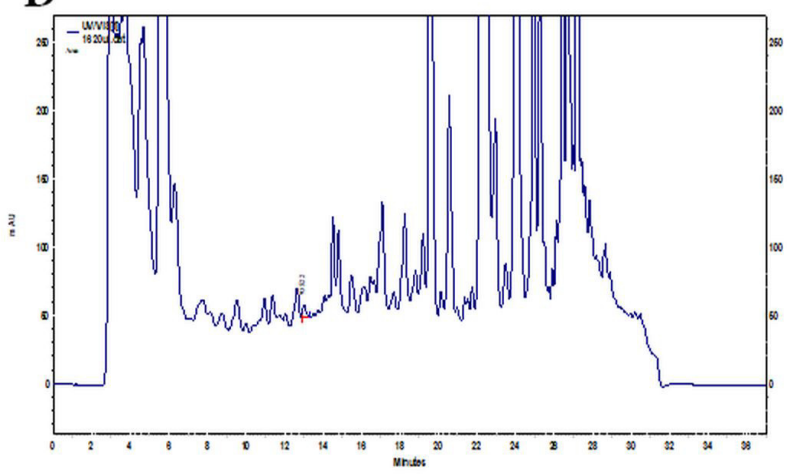

Fig. 5. Spectrum chromatograms of quercetin available in the aerial parts (stems and leaves) of three-month-old seedlings of Glycyrrhiza glabra treated with $\mathrm{AgNO}_{3}$ at different concentration. $0 \mathrm{mg} \mathrm{L}^{-1}$ (A), $2 \mathrm{mg} \mathrm{L}^{-1}(\mathrm{~B}), 4 \mathrm{mg} \mathrm{L} \mathrm{L}^{-1}$ (C), $8 \mathrm{mg} \mathrm{L} \mathrm{L}^{-1}$ (D), $10 \mathrm{mg}$ $\mathrm{L}^{-1}(\mathrm{E})$. Chromatograms of quercetin spectra at various concentrations of $\mathrm{AgNO}_{3}$, show the presence of this compound with an absorption peak in approximately the thirteenth minute. Y-axis: Intensity of quercetin absorption in unit of mAU. X-axis: Retention Time (RT) in unit of minute 
A

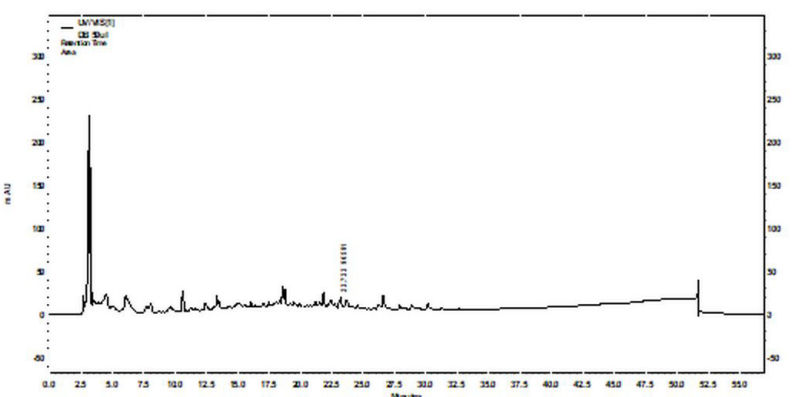

C

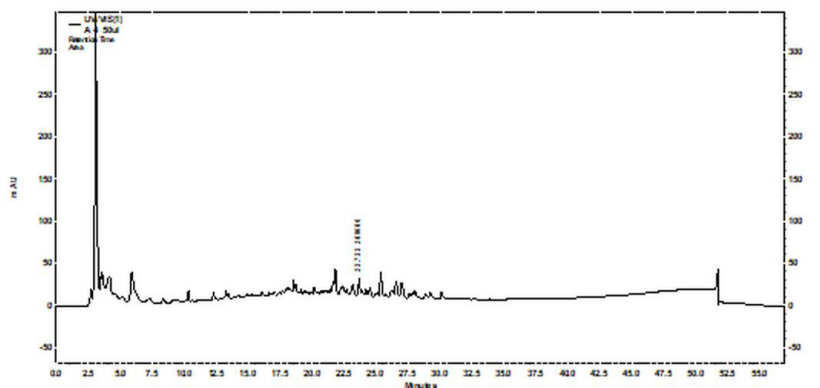

E

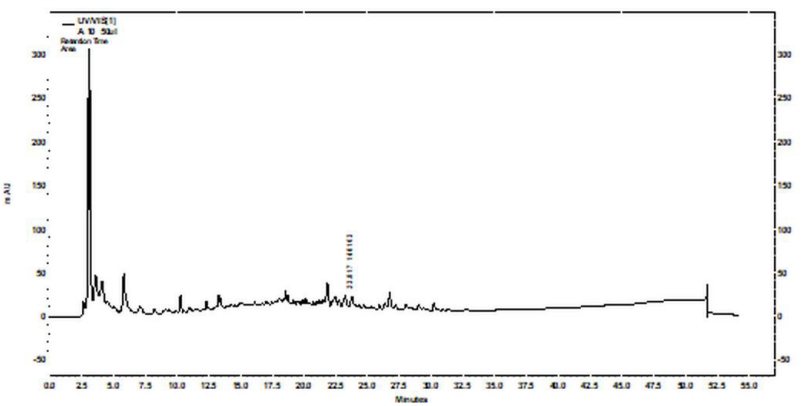

B

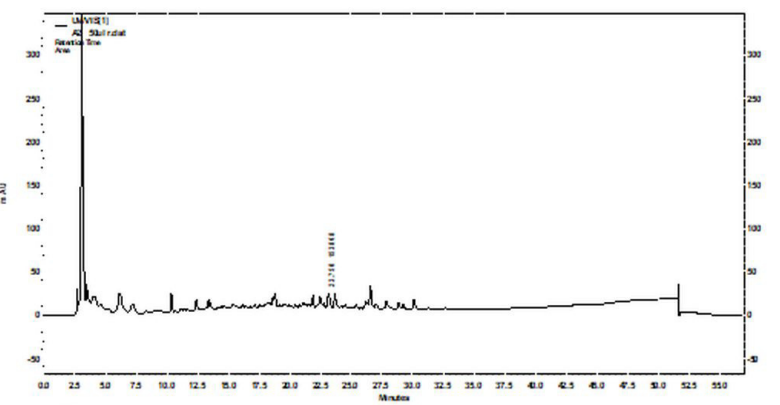

D

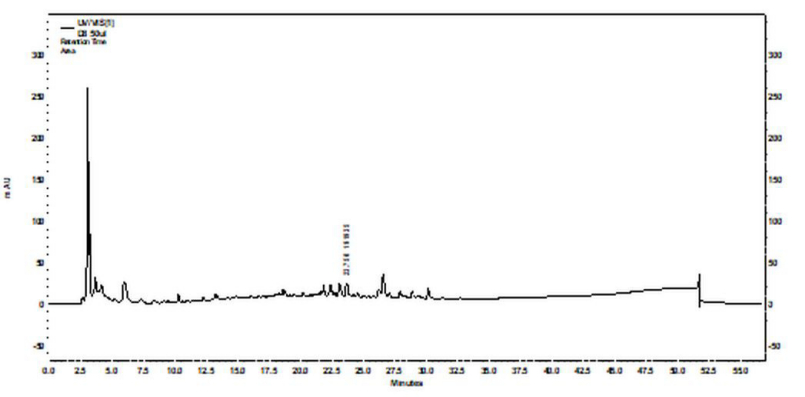

Fig. 6. Spectrum chromatograms of glycyrrhizin available in the roots of Glycyrrhiza glabra seedlings treated with $\mathrm{AgNO}_{3}$ at different concentration. $0 \mathrm{mg} \mathrm{L}^{-1}(\mathrm{~A}), 2 \mathrm{mg} \mathrm{L}^{-1}(\mathrm{~B}), 4 \mathrm{mg} \mathrm{L}^{-1}(\mathrm{C}), 8 \mathrm{mg} \mathrm{L}^{-1}(\mathrm{D}), 10 \mathrm{mg} \mathrm{L}^{-1}$ (E). Chromatograms of glycyrrhizin spectra at various concentrations of $\mathrm{AgNO}_{3}$, show the presence of this compound with the appearance of absorption peaks in approximately the twenty-fourth minute. Y-axis: Intensity of glycyrrhizin absorption in unit of mAU. X-axis: Retention Time (RT) in unit of minute

A

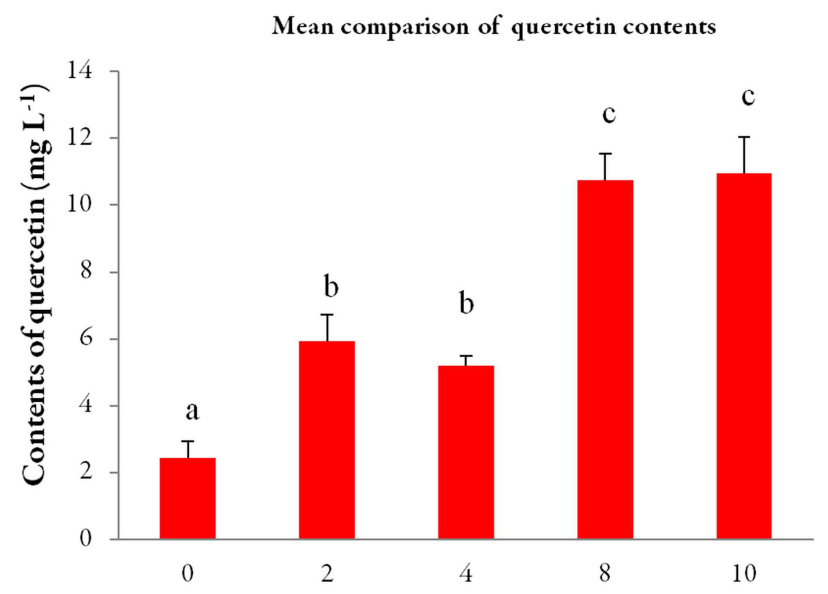

Concentrations of $\mathrm{AgNO} 3\left(\mathrm{mg} \mathrm{L}^{-1}\right)$
B

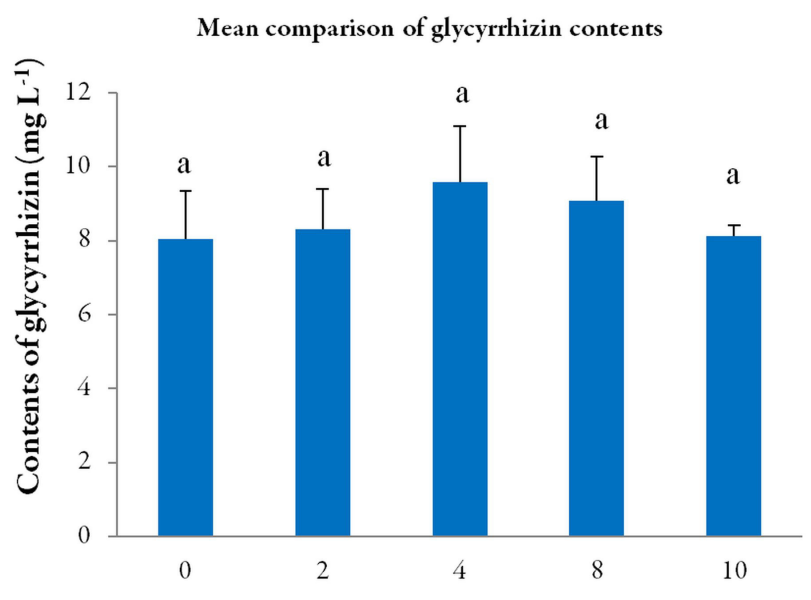

Concentrations of $\mathrm{AgNO} 3\left(\mathrm{mg} \mathrm{L}^{-1}\right)$

Fig. 7. Mean comparison of quercetin (A) and glycyrrhizin (B) contents at different concentrations of $\mathrm{AgNO}_{3}$. Values are the mean \pm standard error and the different letters are significantly different at $\mathrm{P} \leq 0.05$ using Duncan's multiple range. The results show the increase of quercetin and glycyrrhizin at different concentrations of $\mathrm{AgNO}_{3}$ as compared with control $\left(0 \mathrm{mg} \mathrm{L}^{-1}\right)$ 
Fryzova et al., 2018). Evidence has shown that plants reduce the toxicity of these radicals through enzymatic and nonenzymatic antioxidant activity (Racchi, 2013). Superoxide dismutase (SOD), one of plants defense enzymes, is increased under stress conditions caused by heavy metals (Sharma and Dubey, 2005; Groppa et al., 2007). This enzyme plays a key role in the conversion of superoxide radical $\left(\mathrm{O}_{2}^{-}\right)$into hydrogen peroxide (Perry et al., 2010). Hydrogen peroxide as a signaling molecule induces the production of antioxidants such as flavonoids (Agati $e t$ al., 2012). Under stress conditions such as exposure to heavy metals, plant non-enzymatic defense includes the production of secondary metabolites and antioxidant compounds such as flavonoids that causes preservation and survival of plants (Racchi, 2013; Sytar et al., 2013; Kubalt, 2016). Studies have shown that due to the reducing property, flavonoids increase the stability of the cell wall and create a physical barrier to protect the cells against the heavy metals (Diaz et al., 2001). It is reported that, under oxidative stress, secondary metabolites are increased to maintain metabolic activity and help to increase the tolerance of cells (Nammi et al., 2003).

According to the contents, it seems that in this research, the stress caused by the application of $\mathrm{AgNO}_{3}$ induced enzymatic and non-enzymatic defense systems and thus the biosynthesis of quercetin and glycyrrhizin was increased to maintain the survival of the plant. In some experiments, it is observed that the activity of defense mechanisms increases as oxidative stress becomes more sever (Wong et al., 2006).

This may be due to the further increase of quercetin content at higher concentrations of $\mathrm{AgNO}_{3}(8$ and $10 \mathrm{mg} \mathrm{L}$ $\left.{ }^{1}\right)$, compared with lower concentrations $\left(2\right.$ and $\left.4 \mathrm{mg} \mathrm{L}^{-1}\right)$. In addition, there are several reports on anti-ethylene effect of $\mathrm{AgNO}_{3}$ on in vitro culture conditions (Curtis, 1981; Turhan, 2004; Kumar et al., 2009; Harwansh et al., 2011; Tamimi, 2015). Since the high concentrations of ethylene inhibit the production of secondary metabolites (Zhang, 2004), it seems that the positive effect of silver ions $\left(\mathrm{Ag}^{+}\right)$on production and increase of secondary metabolites, including flavonoids and terpenoids could be related to its inhibitory effect on the activity or synthesis of ethylene.

In studying the effect of abiotic elicitors on Salvia miltiorrhiza, it was found that the $\mathrm{Ag}^{+}$ions had the greatest effect on production of phenolic compounds as compared with other ions and also it has shown that these elicitors like $\mathrm{AgNO}_{3}$ induces the activation of gene expression responsible for biosynthesis of plant metabolites in in vitro conditions (Naik and Al-Khayri, 2016). As a result, it seems that this can lead to the biosynthesis and accumulation of secondary plant compounds.

The use of $\mathrm{AgNO}_{3}$ at a concentration of $5.887 \times 10^{-4}$ $\mathrm{mol} / \mathrm{L}$ in the culture medium of Silybum marianum $\mathrm{L}$. and after $72 \mathrm{~h}$, led to the increased production of flavonoid compounds (Vildova et al., 2016). In a study on Ononis arvensis $\mathrm{L}$., it was reported that $0.5 \mathrm{mg}$ of $\mathrm{AgNO}_{3}$ in the culture medium could increase the flavonoid content (Tumova and Polivkova, 2006). The results are consistent with the results of this study. It should be noted that the response of plants to heavy metals could be different depending on the metal concentration and time of stress.

\section{Conclusions}

Our results clearly showed that this method and the use of $\mathrm{AgNO}_{3}$ elicitor with different concentrations $(0,2,4,8$, $10 \mathrm{mg} \mathrm{L}^{-1}$ ) in the culture medium of Glycyrrhiza glabra could be a practical method to produce more quercetin and glycyrrhizin with medicinal value. It should be noted that the use of higher concentrations of $\mathrm{AgNO}_{3}$ is recommended for a significant increase in glycyrrhizin content. Further pharmacological studies on this compound are recommended to optimize the use and consumption of quercetin and glycyrrhizin based on the method used in this research.

\section{Acknowledgements}

The authors would like to thank Engineer Mohammadreza Masoumian, Applied Chemistry Expert in Malek-Ashtar University, Tehran, Iran.

\section{References}

Agati G, Azzarello E, Pollastri S, Tattini M (2012). Flavonoids as antioxidants in plants: location and functional significance. Plant Science 196:67-76.

Bais HP, Sudha GS, Ravishankar GA (2000). Putrescine and silver nitrate influences shoot multiplication, in vitro flowering and endogenous titers of polyamines in Cichorium intybus L. cv. Lucknow local. Journal of Plant Growth Regulation 19(2):238-248.

Bota C, Deliu C (2011). The effect of copper sulphate on the production of flavonoidsin Digitalis lanata cell cultures. Farmacia 59(1):113-118.

Bourgaud F, Gravot A, Milesi S, Gontier E (2001). Production of plant secondary metabolites: a historical perspective. Plant Science 161(5):839-851.

Chondrogianni N, Kapeta S, Chinou I, Vassilatou K, Papassideri I, Gonos ES (2010). Anti-ageing and rejuvenating effects of quercetin. Experimental Gerontology 45(10)::63-771.

Curtis RW (1981). Light requirement for $\mathrm{AgNO}_{3}$ inhibition of ethrelinduced leaf abscission from cuttings of $V$ igna radiata. Plant Physiology 68(6):1249-1252.

Dastgir G, Rizvi MA (2016). Glyoyrhiza glabra L. (Liquorice). Pakistan Journal of Pharmaceutical Sciences 29(5):1727-1733.

Díaz J, Bernal A, Pomar F, Merino F (2001). Induction of shikimate dehydrogenase and peroxidase in pepper (Capsicum annum $\mathrm{L}$.) seedlings in response to copper stress and its relation to lignification. Plant Science 161(1):179-188.

Dmitriensko SG, Kudrinskaya VA, Apyari VV (2012). Methods of extraction, preconcentration and determination of quercetin. Journal of Analytical Chemistry 67:299-311.

Edwards RL, Lyon T, Litwin SE, Rabovsky A, Symons JD, Jalili T (2007). Quercetin reduces blood pressure in hypertensive subjects. The Journal of Nutrition 137(11):2405-2411.

Feild TS, Lee DW, Holbrook NM (2001). Why leaves turn red in autumn. The role of anthocyanins in senescing leaves of red-osier dogwood. Plant Physiology 127(2):566-574. 
150

Fryzova R, Pohanka M, Martinkova P, Cihlarova H, Brtnicky, M, HladkyJ, KynickyJ (2018). Oxidative stress and heavy metals in plants. Reviews of Environmental Contamination and Toxicology Volume 245:129-156.

Fuente CDL, Ortega-Ortiz H, Benavides-Mendoza A, Sandoval-Rangel A (2014). Effect of the application of silver nitrate on antioxidant status in watermelon plants. Pakistan Journal of Botany 46(5):1843-1846.

Fukai T, Cai B-s, Maruno K, Miyakawa Y, Konishi M, Nomura T (1998). An isoprenylated flavanone from Glycyrrbiza glabra and rec-assay of licorice phenols. Phytochemistry 49(7):2005-2013.

Groppa MD, Tomaro ML, Benavides MP (2007). Polyamines and heavy metal stress: the antioxidant behavior of spermine in cadmium-and copper-treated wheat leaves. Biometals 20(2):185-195.

Harwansh R, Patra K, Pareta S, Singh J, Biswas R (2011). Pharmacological studies on Glycyrrbiza glabra: a review. Pharmacologyonline 2(1):10321038.

Jaimand K, Ahrabi Asli H, Behrad Z (2013). Extraction and determination of quercetin and kampferol in Foeniculum vulgare Mill. Iranian Journal of Medicinal and Aromatic plants 29:681-691.

Kanwal H, Sherazi BA (2017). Herbal medicine: Trend of practice, perspective, and limitations in Pakistan. Asian Pacific Journal of Health Sciences 4(4):6-8.

Karaogul E, Parlar P, Parlar H, Alma MH (2016). Enrichment of the gycyrrhizic acid from licorice roots (Glycyrrhiza glabra L.) by isoelectric focused adsorptive bubble chromatography. Journal of Analytical Methods in Chemistry 7201740.

Khalaf I, Vlase L, Lazar D, Corciova A, Ivanescu B, Lazar MI (2010). HPLC-UV-MS study of polyphenols from Glycyrrhiza glabra. Farmacia 58(4):416-421.

Kubalt K (2016). The role of phenolic compounds in plant resistance. Biotechnology and Food Science 80(2):97-108.

Kumar S, Pandey AK (2013). Chemistry and biological activities of flavonoids: an overview. The Scientific World Journal 162750.

Kumar V, Parvatam G, Ravishankar GA (2009). $\mathrm{AgNO}_{3}$ : A potential regulator of ethylene activity and plant growth modulator. Electronic Journal of Biotechnology 12(2):8-9.

Larson AJ, Symons JD, Jalili T (2010). Quercetin: a treatment for hypertension? - A review of efficacy and mechanisms. Pharmaceuticals 3(1):237-250.

Liao J, Qu B, Zheng N (2016). Extraction of gycyrrhizic acid from Glycyrrhiza uralensis using ultrasound and its process extraction model. Applied Sciences 6(11):319.

Maalik A, Khan FA, Mumtaz A, Mehmood A, Azhar S, Atif M, Tariq I (2014). Pharmacological applications of quercetin and its derivatives: a short review. Tropical Journal of Pharmaceutical Research 13(9):15611566.

Mierziak J, Kostyn K, Kulma A (2014). Flavonoids as important molecules of plant interactions with the environment. Molecules 19(10):1624016265.

Mlcek J, Jurikova T, Skrovankova S, Sochor J (2016). Quercetin and its antiallergic immune response. Molecules 21(5):623.

Murashige T, Skoog F (1962). A revised medium for rapid growth and bioassays with tobacco tissue cultures. Physiologia Plantarum 15(3): $473-497$.
Nagaich U, Gulati N, Chauhan S (2016). Antioxidant and Antibacterial Potential of Silver Nanoparticles: Biogenic Synthesis Utilizing Apple Extract. Journal of Pharmaceutics 7141523.

Naik P, Al-Khayri J (2016). Impact of abiotic elicitors on in vitro production of plant secondary metabolites: a review. Journal of Advanced Research in Biotechnology 1(2):1-7.

Nammi S, Boini MK, Lodagala SD, Behara RBS (2003). The juice of fresh leaves of Catharanthus roseus Linn. reduces blood glucose in normal and alloxan diabetic rabbits. BMC Complementary and Alternative Medicine3(1):4.

Panche AN, Diwan AD, Chandra SR (2016). Flavonoids: an overview.Journal of Nutritional Science 5, e47.

Patel H, Krishnamurthy R(2013). Elicitors in plant tissue culture. Journal of Pharmacognosy and Phytochemistry 2(2):60-65.

Perry J, Shin D, GetzoffE, Tainer J (2010). The structural biochemistry of the superoxide dismutases. Biochimica et Biophysica Acta (BBA)Proteins and Proteomics 1804(2):245-262.

Racchi ML (2013). Antioxidant defenses in plants with attention to Prunus and Citrus spp. Antioxidants 2(4):340-369.

Raja R, Sreenivasulu M (2015). Medicinal plants secondary metabolites used in pharmaceutical importance - An overview. World Journal of Pharmacy and Pharmaceutical Sciences 4(4):436-447.

Ramirez-Estrada K, Vidal-Limon H, Hidalgo D, Moyano E, Golenioswki M, Cusidó RM, Palazon J (2016). Elicitation, an effective strategy for the biotechnological production of bioactive high-added value compounds in plant cell factories. Molecules 21(2):182.

Ranganathan V,Punniamurthy N (2013). Estimation of phenol contents in Glycirrbiza glabra by thin layer chromatography and spectrophotometry. International Journal of Agricultural Sciences and Veterinary Medicine 1(3):2427.

RatesSMK(2001). Plants as source of drugs. Toxicon 39(5):603-613.

Schäfer H, Wink M (2009). Medicinally important secondary metabolites in recombinant microorganisms or plants: progress in alkaloid biosynthesis. Biotechnology Journal 4(12):1684-1703.

Seca AM, Pinto DC (2018). Plant secondary metabolites as anticancer agents: successes in clinical trials and therapeutic application. International Journal of MolecularSciences 19(1):263.

Sewelam N, Kazan K, Schenk PM (2016). Global plant stress signaling: reactive oxygen species at the cross-road. Frontiers in Plant Science 7:187.

Shabani L, Ehsanpour AA, Asghari G, Emami J (2009). Glycyrrhizin production by in vitro cultured Glycyrrbiza glabra elicited by methyl jasmonate and salicylic acid. Russian Journal of Plant Physiology 56(5): 621-626.

Shakeran Z, Keyhanfar M, Asghari G, Ghanadian M (2015). Improvement of atropine production by different biotic and abiotic elicitors in hairy root cultures of Datura metel. Turkish Journal of Biology39(1): 111118.

Sharma P, Dubey RS (2005). Lead toxicity in plants. Brazilian Journal of Plant Physiology 17(1):35-52.

Sharma P, Jha AB, Dubey RS, Pessarakli M (2012). Reactive oxygen species, oxidative damage, and antioxidative defense mechanism in plants under stressful conditions. Journal of Botany 217037. 
Singh B, Mungara P, Nivsarkar M, Anandjiwala S (2009). HPTLC densitometric quantification of gycyrrhizin, gycyrrhetinic acid, apigenin, kaempferol and quercetin from Glycyrrbiza glabra. Chromatographia 70(11-12):1665.

Smetanska I (2008). Production of secondary metabolites using plant cell cultures. Food Biotechnology 111:187-228.

Sytar O, Kumar A, Latowski D, Kuczynska P, Strzałka K, Prasad M (2013). Heavy metal-induced oxidative damage, defense reactions, and detoxification mechanisms in plants. Acta Physiologiae Plantarum 35(4):985-999.

Tamimi SM (2015). Effects of ethylene inhibitors, silver nitrate $\left(\mathrm{AgNO}_{3}\right)$, cobalt chloride $(\mathrm{CoCl} 2)$ and aminooxyacetic acid $(\mathrm{AOA})$, on in vitro shoot induction and rooting of banana (Musa acuminata L.). African Journal of Biotechnology 14:2511-2516.

Tholl D (2015). Biosynthesis and biological functions of terpenoids in plants. In: Schrader J, Bohlmann J (Eds). Biotechnology of isoprenoids. Advances in Biochemical Engineering/Biotechnology. Springer, Cham 148:63-106.

Tian M, Yan H, Row KH (2008). Extraction of gycyrrhizic acid and gabridin from licorice.International Journal of Molecular Sciences 9(4):571-577.

Tiwari R, Rana C (2015). Plant secondary metabolites: a review. International Journal of Engineering Research and General Science 3:661-670.

Treutter D (2006). Significance of flavonoids in plant resistance: a review. Environmental Chemistry Letters 4(3):147.

Tripathy BC, Oelmüller R (2012). Reactive oxygen species generation and signaling in plants. Plant Signaling \& Behavior 7(12):1621-1633.

Tumova L, Polivkova D (2006). Effect of $\mathrm{AgNO}_{3}$ on the production of flavonoids by the culture of Ononis arvensis L in vitro. Ceska Slov Farm 55(4):186-188.
Turhan $\mathrm{H}$ (2004). The effect of silver nitrate (ethylene inhibitor) on in vitro shoot development in potato (Solanum tuberosum L.). Biotechnology 3(1):72-74.

Vildova A, Hendrychova H, Kubes J, Tumova L (2016). Influence of $\mathrm{AgNO}_{3}$ Treatment on the Flavonolignan production in cell suspension culture of Silybum marianum (L.) Gaertn. World Academy of Science, Engineering and Technology, International Journal of Biological, Biomolecular, Agricultural, Food and Biotechnological Engineering8(8):959-962.

Wink M (2010). Function and biotechnology of plant secondary metabolites. Annual Plant Reviews 39.

Wong SP, Leong LP, Koh JHW (2006). Antioxidant activities of aqueous extracts of selected plants. Food Chemistry 99(4):775-783.

Yang L, Wen KS, Ruan X, Zhao YX, Wei F, Wang Q (2018). Response of plant secondary metabolites to environmental factors. Molecules 23(4):762.

Zeka K, Ruparelia K, Arroo RR, Budriesi R, Micucci M (2017). Flavonoids and their metabolites: prevention in cardiovascular diseases and diabetes. Diseases 5(3):19.

Zhang Y (2004). Cancer-preventive isothiocyanates: measurement of human exposure and mechanism of action. Mutation Research / Fundamental and Molecular Mechanisms of Mutagenesis 555(1):173190.

ZhaoJ, Fujita K, Sakai K(2005). Oxidative stress in plant cell culture: a role in production of $\beta$-thujaplicin by Cupresssus lusitanica suspension culture. Biotechnology and Bioengineering 90(5):621-631. 